\title{
Ultrasound guidance during hysteroscopy
}

\section{Mini review}

Uterine fibroids are the most common benign tumours of female genital tract. ${ }^{1}$ They occur in $20-25 \%$ of women of reproductive age. Fibroids arise from the smooth muscle tissue of myometrium. Majority of fibroids are asymptomatic. Most of the symptoms are menstrual disorders, pain and fertility issues. ${ }^{2}$ Fibroids are often described according to their location in the uterus. ${ }^{3}$ Submucous fibroids (SF) derive from myometrial cells just below the endometrium and protrude in to the endometrial cavity. Hysterectomy and hysterotomy were the two standard methods for surgical treatment of symptomatic SF for a long time. Hysteroscopy with the development of technology became the gold standard method in treatment of all non-cancerous intrauterine lesions. Hysteroscopic myomectomy (HM) currently gold standard minimally invasive and safe surgical procedure in treatment of SF. ${ }^{4}$ It is usually performed as outpatient surgery. Most patients return to full activity within 48 hours.

The most commonly used classification system for SF was described by the European Society of Hysteroscopy (ESH): ${ }^{5}$

i. G0 - Completely within the endometrial cavity

ii. G1 - Extend less than 50 percent into the myometrium

iii. G2 - Extend 50 percent or more within the myometrium

Common complications of HM are uterine perforation, incomplete removal of fibroid bleeding, postoperative adhesion and electrolyte imbalance. Complete resection of fibroids in HM depends upon surgical skill and experience. It's not possible to recognise the margins of the fibroid by hysteroscopy. Incomplete removal is more common in $\mathrm{G} 2$ fibroids. ${ }^{6}$ Several studies showed that incomplete resection rates ranges from 5 to 17 percent. ${ }^{6,7}$ Several techniques described for HM. Resectoscopic slicing is the gold standard technique for G0 fibroids. ${ }^{8}$ This technique has excellent results in G0 fibroids. There is no gold standard technique regarding hysteroscopic excision of sub mucous fibroids with a major intramural component (G1 and G2 fibroids). Several surgical techniques described for avoid from complications forremoval of G1 and G2 fibroids. Resectoscopic slicing is the classic technique for HM. Two-step procedure - first described by Donnez et al., ${ }^{9}$ - represents an effective technique which includes combination of hormonal treatment and hysteroscopic laser surgery. ${ }^{9}$ Main problem of this procedure is this method requires two surgical interventions. This procedure also expensive too. Cold loop technique allows total excision of fibroid in one step but needs experienced surgeon. ${ }^{10}$ This could be a disadvantage for the beginner medical stuff. Ultrasound guidance during gynecological surgery may prove safety and accuracy of the procedure. ${ }^{11}$ Also continuous visualisation can shorten the operation time. Obesity and a scarred abdomen (eg, after cesarean deliveries) may diminish transabdominal image quality.

Korkmazer et al., ${ }^{12}$ used ultrasound guidance during HM in 64 patients. They showed ultrasound guidance during HM provides complete removal and safety. ${ }^{12}$ There was no residual fibroid in this serie. Uterine perforation during procedure not occurred. The increased safety and complete removal rate in ultrasound guided hysteroscopy procedures were reported by several studies was encouraging. However, the technique requires an additional person to hold the transabdominal transducer. Ultrasound guidance during
Volume 4 Issue I - 2017

\author{
Engin Korkmazer \\ Department of Gynecology and Obstetrics, Giresun University \\ Faculty of Medicine, Turkey
}

Correspondence: Engin Korkmazer, Department of Gynecology and Obstetrics, Giresun University Faculty of Medicine, Giresun, Turkey, Tel +905059I28662, Email mediko196@hotmail.com

Received: December 13, 2016 | Published: January 17, 2017

hysteroscopy also reduces the laparoscopy assisted hysteroscopy procedure rates. Kresowik et al., ${ }^{13}$ showed ultrasound guidance cost less than laparoscopy assisted procedures. ${ }^{13} \mathrm{~A}$ study by Coccia et al., ${ }^{14}$ found ultrasound guidance to be superior to laparoscopic guidance in patients undergoing hysteroscopic myomectomy and metroplasty. ${ }^{14}$ Ultrasound guidance during HM can shorten the operation time. The ultrasound assisted hysteroscopic surgery provides high-resolution images of the uterine cavity during all stages of the procedure, provides high satisfaction rate for the operator, and increases the complete removal rate of the fibroid and safety of the procedure.

\section{Acknowledgements}

None.

\section{Conflict of interest}

The author declares no conflict of interest.

\section{References}

1. Baird DD, Dunson DB, Hill MC, et al. High cumulative incidence of uterine leiomyoma in black and White women: ultrasound evidence. Am J Obstet Gynecol. 2003;188(1):100-107.

2. Gupta S, Jose J, Manyonda I. Clinical presentation of fibroids. Best Pract Res Clin Obstet Gynaecol. 2008;22(4):615-626.

3. Munro MG, Critchley HO, Fraser IS. The FIGO classification of causes of abnormal uterine bleeding in the reproductive years. Fertil Steril. 2011;95(7):2204-2208.

4. Di Spiezio Sardo A, Mazzon I, Bramante S, et al. Hysteroscopic myomectomy: a comprehensive review of surgical techniques. Hum Reprod Update. 2008;14(2):101-119.

5. Wamsteker K, Emanuel MH, de Kruif JH. Transcervical hysteroscopic resection of submucous fibroids for abnormal uterine bleeding: results regarding the degree of intramural extension. Obstet Gynecol. 1993;82(5):736-740.

6. Polena V, Mergui JL, Perrot N, et al. Long-term results of hysteroscopic myomectomy in 235 patients. Eur J Obstet Gynecol Reprod Biol. 2007;130(2):232-237.

7. Van Dongen H, Emanuel MH, Smeets MJ, et al. Follow-up after incomplete hysteroscopic removal of uterine fibroids. Acta Obstet Gynecol Scand. 2006;85(12):1463-1467. 
8. Murakami T, Tamura M, Ozawa Y, et al. Safe techniques in surgery for hysteroscopic myomectomy. J Obstet Gynaecol Res. 2005;31(3):216-223.

9. Donnez J, Gillerot S, Bourgonjon D, et al. Neodymium: YAG laser hysteroscopy in large submucous fibroids. Fertil Steril. 1990;54(6):9991003.

10. Mazzon I. Nuova tecnica per la miometomia isteroscopica: enucleazione con ansa fredda. In: Cittadini E, et al. Editors. Testo-Atlante di Chirurgia Endoscopica Ginecologica. Palermo, Italy; 1995. p. 1-33.

11. Timor-Trisch IE, Masch RJ, Goldstein SR, et al. Transvaginal ultrasoundassisted gynecologic surgery: Evaluation of a new device to improve safety of intrauterine surgery. Am J Obstet Gyneco. 2003;189(4):1074-1079.
12. Korkmazer E, Tekin B, Solak N. Ultrasound guidance during hysteroscopic myomectomy in G1 and G2 submucous myomas: for a safer one step surgery. Eur J Obstet Gynecol Reprod Biol. 2016;203:108-111.

13. Kresowik JD, Syrop CH, Van Voorhis BJ, et al. Ultrasound is the optimal choice for guidance in difficult hysteroscopy. Ultrasound Obstet Gynecol. 2012;39(6):715-718.

14. Coccia ME, Becattini C, Bracco GL, et al. Intraoperative ultrasound guidance for operative hysteroscopy. A prospective study. J Reprod Med. 2000;45(5):413-418 